\title{
Examining Life Course Transitions of Young People with Disabilities: The ACEE Alumni Study
}

\author{
Cornelia Schneider ${ }^{1}$, Saad Chahine ${ }^{2}$, Brenda Hattie ${ }^{1}$ \\ ${ }^{1}$ Faculty of Education, Mount Saint Vincent University, Halifax, NS, Canada \\ ${ }^{2}$ Centre for Education Research \& Innovation, University of Western Ontario, London, ON, Canada \\ Correspondence: Cornelia Schneider, MSVU, 166 Bedford Hwy, Halifax NS, B3M 2J6, Canada.
}

Received: July 26, 2016 Accepted: August 12, $2016 \quad$ Online Published: August 26, 2016

doi:10.11114/jets.v4i10.1768 URL: http://dx.doi.org/10.11114/jets.v4i10.1768

\begin{abstract}
This article examines the outcomes of the ACEE program, which is a one-year transition program for youth with disabilities, preparing them for the workplace and adult life. In a mixed methods approach, the investigators surveyed sixty-six youth with disabilities who were alumni of the program and followed up in depth with ten alumni in in-depth interviews and focus groups. The results show that the youth are doing well in terms of community participation and mobility. Many of them are active and involved into different social networks, be it with family, friends or community organizations. On the other hand, the study highlights issues in regards to employment and independent living. Employment can be precarious and underpaid, and the alumni's living situation often depends on their families, as there are few other options to them available.
\end{abstract}

Keywords: disability, employment, life course transition, social participation, independent living, youth

\section{Introduction}

The following article emerges from a long-standing collaboration between university researchers at Mount Saint Vincent University in Halifax, Nova Scotia, Canada, and stakeholders of the ACEE program (Access to Community, Employment and Education) located in the same city. It examines how young people primarily with learning disabilities experience the transition from school to the workplace and adulthood, and how their desires for access and social participation are being addressed in the communities in which they live.

Historically, people with disabilities have been excluded from many domains of society. Typically cast as eternal children who were unable to support themselves, little thought was given to their transition from a life of dependence on others to one of autonomy. However, over the past two decades, particularly in OECD countries, a shift has taken place, partly due to the activism and advocacy of people with disabilities and their families, who have demanded the right to participate in all aspects of society (Campbell \& Oliver, 1996; Charlton, 1998), and also due to the increasing tendency to see disability as a human rights issue (Breslin \& Yee, 2002; Blanck, 2004). Whereas historically, persons with disabilities were institutionalized and segregated from the broader society, since the 1970s, policies have shifted toward the removal of barriers, inclusivity and accessibility to all domains of social life, and an increase in social awareness (United Nations, 2003). As a result, increasing numbers of people with disabilities have found employment, and have been able to leave the realm of social institutions to lead independent and self-determined lives.

\section{Background Literature}

Despite gains made over the past few decades, research indicates that persons with disabilities continue to face challenges in accessing meaningful work (Holwerda, van der Klink, Groothoff, \& Brouwer, 2012; Howlin, 2003; Shattuck et al., 2012). These challenges are evident as early as secondary school. Using data from the National Longitudinal Transition Study-2, a 10-year study of the experiences of youth with disabilities aged 13-16 who received special education services in the 2000-2001 school year, it has been shown that only $50 \%$ of those in secondary school had an opportunity to participate in any on or off campus work training opportunities (Wagner, Newman, Cameto, Levine, \& Marder, 2003), and only $14.5 \%$ had been employed after school or during the summer the previous year (Wagner, Cadwallader \& Marder, 2003). Few had opportunities to participate in a workplace as an intern or apprentice, to do a student placement, or to job shadow (Wagner, Newman et al., 2003). After graduation, employment prospects 
continue to be poor. For instance, a study conducted by Newman et al (2011) indicates that up to 8 years after leaving high school, only $63.2 \%$ of young adults had worked since graduation and only $37.2 \%$ of these were currently employed at the time of the survey. A longitudinal study conducted in Canada (Canadian Centre for Disability Studies, 2004) exploring the experiences of 79 students with disabilities transitioning from college and university to employment found that only $52 \%$ were employed full time, and only $42 \%$ were employed in a field of their choice. Obstacles to employment included: attitudes of employers, lack of accessible transportation, lack of physical and communication accessibility of the employer, and lack of resources for needed supports. Studies have revealed that the transition from school to post-secondary education and/or work can be challenging for students with disabilities (Chambers, Rabren \& Dunn, 2009; Wehmeyer \& Palmer, 2003). Supports and services that exist throughout school are difficult to find and/or re-establish in adulthood (McDonnell \& Hardman, 2010; Wehman, 2006). This study examines the lives of individuals who participated in a program that was created to address the need of support in this area.

\section{The ACEE Alumni Study-methodology}

The ACEE program (Access to Community, Education and Employment) caters to young people primarily with learning disabilities who have been graduating from high schools in the Halifax Regional Municipality in the previous year. The one-year transition program is run by Independent Living Nova Scotia, Affirmative Ventures Nova Scotia and the Halifax Regional School Board, and funded by the Province of Nova Scotia \& Departments of Community Services and Education. It offers workshops on job-related literacy, numeracy, independent living skills, career exploration and employment orientation. The workshops and classes are offered at the Nova Scotia Community College with teachers from the school board and job coaches and developers from Independent Living Nova Scotia. The other components of the program are work placements in training businesses run by Affirmative Ventures Nova Scotia, which provides job development and job coaching. Not only does the program provide training, it also seeks to support the youth to gain meaningful employment at the end of the year. The training businesses focus on retail experience, with training and experiences in merchandising, receiving, cash training, storekeeping, etc. They are operating in the community, and are focusing exclusively on preparing trainees for work in the community. The ACEE program is open to any youth who have graduated from high school who have had an Individualized Program Plan, and who need support to transition to work life or further education. It does not focus on any particular type of disability, but from personal communications and observations, many of its participants appear to have been diagnosed with a learning disability or an intellectual disability.

A previous research project focused on the experience of the young people with disabilities. Using an ethnographic approach, the investigator spent one year in one of the training businesses getting trained together with the youth with disabilities. The results of that research has been published, conceptualizing the experience of those youth with disabilities in the framework of sociology of emotions (see Schneider, 2010). It showed how youth with disabilities undergo a process of learning how to manage their emotions in the workplace as a part of being successful in the work world.

Following this first study, the ACEE stakeholders and the team of investigators became interested in the overall impact of the ACEE program. The program had existed since 2005, so it was felt that it was time to get a sense of what impact the program might have had on the life experience of its alumni. Did the program live up to the needs of its clients? Had the alumni found and retained employment? Were they able to develop sufficient independent living skills in order to live in arrangements to their liking?

In order to answer these questions, a mixed method approach appeared to be the most appropriate. A survey was used to get a strong sense of the current status of a large number of the ACEE alumni, followed by interviews with those who were interested in participating, in order to get a stronger idea of the qualitative experience of the past few years transitioning into adult life. From our perspective, it was important to investigate directly the ACEE alumni themselves rather than their families or professionals surrounding them. Giving a voice to their own personal experience instead of having somebody else speaking for them is an important feature to assess the value of a program, and has been overlooked far too often (Cavet \& Sloper, 2004; Davis, Watson \& Cunningham-Burley, 2000). Secondly, participating in such a project also has an empowering effect on people with disabilities (e.g., see Atkinson, 2004)

The goal of the researchers was to survey seven cohorts of alumni (2005-2012, 143 alumni, which comprised all youth with disabilities who had ever taken the program) and then do follow-up interviews with some participants who were interested in participating.

In order to get a sense of the lives of the alumni, and any possible impact from the ACEE program, we decided to use the logic model of the ACEE program as a basic matrix. We focussed on the intended mid- and long-term outcomes of the model on participants' lives related to the following domains: Work Life, Home Life, Transportation, Leisure, Networks. 
From those five domains that ACEE intends on addressing in its program, we developed both the survey and the interview questions, which were complementary as the survey assessed the quantitative part of the research (employment numbers, job satisfaction, income satisfaction, housing, leisure activities, etc.). We created items for our study and decided which questions could be better addressed using a quantitative or the qualitative approach. In the survey, we also asked the participants about their socioeconomic background, and they could identify their ethnic background if they desired. The interviews then delved more into the qualitative experience of the participants (what are you doing, how is that working for you, how do you feel about your life, friendships, what is your experience, etc). The surveys offered, for the most part, multiple choice for the participants to answer, but also included a few open-ended questions. For example, the question about transportation to work in the survey offered several options, such as taking the bus, walking, getting dropped off, driving, taking the accessible bus. Open-ended questions were asking them, for example, to describe their parents'/carers' work, their living situation, their strengths and their challenges. We also limited the length of the survey and made its language as accessible as possible, so that all of the alumni would be able to participate in the survey.

To recruit alumni, we obtained permission from both the ACEE program and our University Research Ethics Board (UREB) to access a database that contained the last-known contact information of the alumni. Contact information had not always been updated, so the information was often no longer valid, especially for the older cohorts. Thus, we were not able to reach every single alumna who had ever participated in the program, but we tried at least once to reach as many as possible. There was also a low number of refusals to participate in the study, either from parents who did not want their child to participate, or from the alumni themselves who did not wish to take part. We did not specifically collect the number of refusals, as we did not have the permission from our UREB to retain this data.

We collected surveys during an alumni event that was organized by Independent Living Nova Scotia, and contacted other alumni who were not present at that event by phone to provide them an opportunity to complete the survey. For many, we actually had to train research assistants to help the alumni to fill out the questionnaires and to collect their responses. All alumni filled out the survey with the support of the investigators or the research assistants.

Table 1. Gender

\begin{tabular}{lll}
\hline & $\mathbf{n}$ & $\mathbf{\%}$ \\
\hline Male & 38 & $58 \%$ \\
Female & 28 & $42 \%$ \\
\hline
\end{tabular}

By the end of the survey phase, 66 alumni had agreed to participate, which corresponds to $46 \%$ of the entire ACEE alumni population between 2005 and 2012. Of this group of participants, 38 were male and 28 were female, which corresponds to the actual gender ratio in the program (see table 1).

Table 2. Self-Identified Ethnic Background

\begin{tabular}{lll}
\hline & $\mathbf{n}$ & $\mathbf{\%}$ \\
\hline Canadian & 21 & $32 \%$ \\
European & 9 & $13 \%$ \\
African Canadian & 4 & $6 \%$ \\
Non-European & 4 & $6 \%$ \\
First Nations & 2 & $3 \%$ \\
Did Not Disclose & 13 & $20 \%$ \\
Non response & 13 & $20 \%$ \\
\hline
\end{tabular}

15\% identified themselves as part of a visible minority group (e.g., African Nova Scotian, First Nations, Middle Eastern, etc.; see table 2). Overall, the number of participants is acceptable, however, we cannot state that this group would be representative for the whole group of alumni. Average age of the participants was $23(\mathrm{n}=66, \mathrm{SD}=2.81$ ), with the youngest being 17 and the oldest being 31 . See figure 1 and 2 for the distribution of participants related to their age and the year they were enrolled in the ACEE program. There were less participants $(n=2)$ in the study from the 2011 cohort. It was not possible for us to find out why participation from this particular year was in this small number, as the invitations for the alumni event and the following phone interviews went out equally to all alumni of the program. 


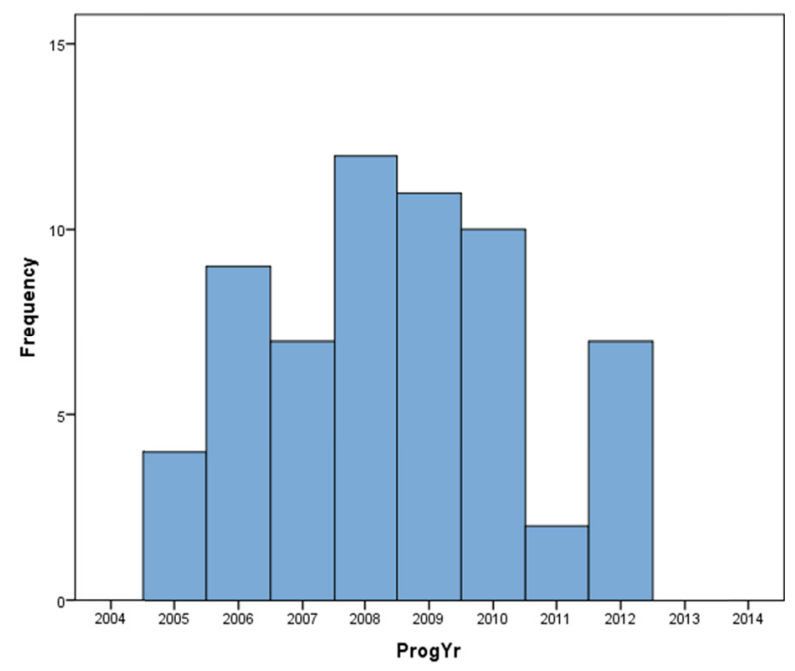

Figure 1. Participants in the ACEE Alumni study according to their year of enrolment

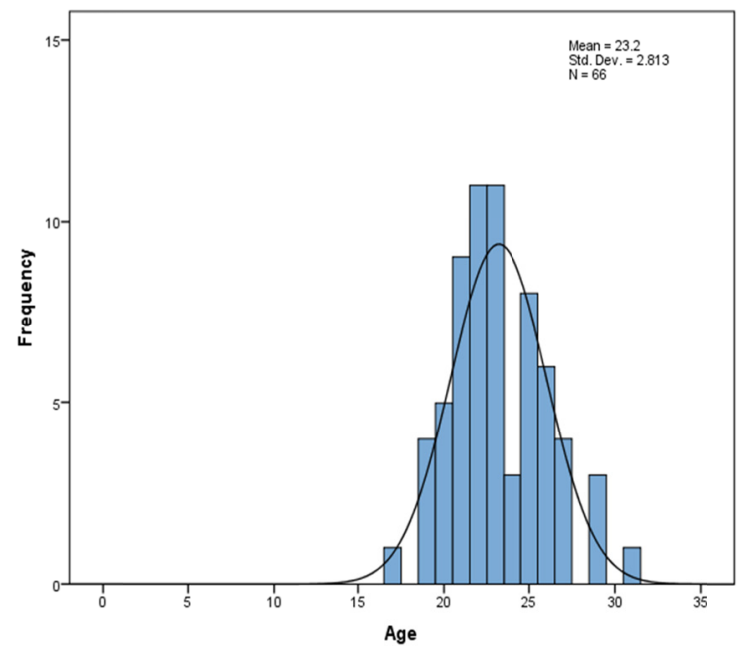

Figure 2. Participants in the ACEE Alumni study according to their age

Finally, of the 66 participants, 10 (5 females, 5 males) agreed to complete an in-depth interview (4 participants) or participate in a group interview (3 pairs) (table 3). One mother asked to be part of her son's interview, so we conducted the interview with both of them together. For the interviews, we investigated the lived experience of the alumni's lives, as we asked them about the five domains identifying the mid- and long-term outcomes of the ACEE program (home life, work life, transportation, leisure, networks). The focus shifted on the participants telling us in depth about their current lives and experiences in those domains (e.g. experience at the workplace with supervisors or co-workers; their friendships and (intimate) relationships; types of leisure activities).

Table 3. Overview of the interview participants

\begin{tabular}{llll}
\hline Name & Cohort year & Professional situation & Living situation \\
Amanda & 2012 & Training program & With the family \\
Anna & 2009 & Unemployed & With the family \\
Barry & 2012 & Unemployed, does internships & With the family \\
Brian & 2006 & Employed & With the family \\
Cathy & 2010 & Unemployed & With the family \\
David & 2008 & Has three jobs & With the family \\
Greg & 2007 & Unemployed, was previously employed & With the family \\
Kate & 2010 & Unemployed, did internships & With the family \\
Salim & 2010 & Unemployed, was previously employed & With the family \\
Sharon & 2008 & Training program & Therapeutic living arrangemen \\
\hline
\end{tabular}

We analyzed the data using SPSS to see if there were any statistically significant results from the survey. However, given the small number of participants, our findings proved not statistically significant. Thus, the data will be presented 
in absolute numbers and percentages. The interview data was transcribed, coded and analyzed by one researcher, and then verified by the rest of the team.

\section{Results}

In this section, we will present our findings following the order of the five domains that were the guiding thread of our inquiry. We will, in each part, present the results from the survey, and then illustrate, emphasize and expand on those results by presenting outcomes from the interviews.

\subsection{Work Life}

Given that one of the major components of the ACEE program is job training, job development and employment, we will first and foremost explore the situation of the ACEE alumni in regards to their occupational situation since leaving the program. Given the low number of respondents, we chose both to present the data in absolute numbers as well as in percentages, intersected by results stemming from the follow-up interviews.

Table 4. Occupational situation

\begin{tabular}{lll}
\hline & $\mathbf{n}$ & $\mathbf{0}$ \\
\hline Employed & 31 & $47 \%$ \\
I'm looking for work/volunteer work/school & 22 & $33 \%$ \\
Volunteer work & 5 & $8 \%$ \\
Other & 5 & $8 \%$ \\
Students & 3 & $5 \%$ \\
\hline
\end{tabular}

As Table 4 shows, almost half of the participants indicated that they were currently employed, while a third indicated that they were currently looking for any type of occupation. We did not ask participants who were currently unemployed how long they had been looking for work. Five participants were volunteering, and three had returned to school in order to further their education or training. The employment numbers of the participants are slightly above the national labour force participation rate for people with disabilities aged 15 to 24 years old (40.1\% according to the 2006 Profile of Disability in Canada (Human Resources and Skills Development Canada, 2006)). We also noticed that employment numbers have been lower in the cohorts since 2008, which might hint to the general employment situation following the recession, which has had an impact on the overall Canadian population.

Overall, looking at the numbers, it appears that the occupational situation of the alumni corresponds with the Canadian national average of employment of people with disabilities. When we did the interviews with some of the participants afterwards, several reported that the quality of their employment situation was not to their satisfaction, especially when it came to the number of hours worked, and it turned out that their number of hours had been reduced without notice or explanation. Greg speaks about this somewhat hidden limitation of his employment:

I(nvestigator):Yeah, you liked that. What about, and the supervisor you had before the one that came in and didn't like you, what was that person like?

$\mathrm{G}(\mathrm{reg})$ : Kind of cranky at me, they weren't giving me any hours, cut back my hours.

I: Oh, even the one before -

G: No, the one that came in that didn't like me. The one before that was super nice, she knew how people with disabilities are like and wanted to give me a chance.

It appears that a few years after their graduation from the ACEE program, some of the participants might not have had sufficient protection and support in order to negotiate work place conflicts, which resulted in several instances in a reduction of workload.

Analyzing the data, we also realized that there were differences in the employment numbers in regards to the socioeconomic background of the participants. Youth with parents employed in the field of education were twice as likely to be employed as those with parents employed in the trades or in retail, where the chance was half and half. As sociologists have noted, parents' educational background and the strategies parents use to support the education and employment of their children must be taken into account in terms of transition into the workplace. Parental cultural and social capital plays an important role in the positive educational and employment outcomes of their children (see e.g., Trainor, 2008, 2010). This support is evident in our interviews, especially when it comes to finding their children work, or when it comes to making sure that things go smoothly in the current occupational situation. For instance, David noted:

Because my Dad helped me get the Daily News job, actually, somebody from his work did, because the boss that I had before, he's not, it was actually called Benchmark Advertising, before, and it's just under the Daily News, and they used to, one of them used to work out there with, at the Daily News as well, so... 
His father's social capital supported his job search at the end of the ACEE program. In the interview with an alumna, Brian, and his mother, the latter explained how she viewed her role in making her son's work experience smooth:

But I'm a real hands-on mom, so I would often go in and see if there was any problems that he needed help with and I would sometimes just spend an hour with him and job shadow, just to help him with different things, and uh, you know, that was my job as a mom.

The mother's cultural capital is at work in this case, as she gages very well which strategies she needs to use, so that her son is able to retain his job without too many conflicts with the employers.

Table 5. Satisfaction with current situation

\begin{tabular}{lll}
\hline & n & \% \\
\hline I'm excited about the work/volunteer work/school I do & 25 & $38 \%$ \\
I'm looking for other work/volunteer work/school & 15 & $23 \%$ \\
I have good days and bad days & 14 & $21 \%$ \\
Other & 4 & $6 \%$ \\
Omitted & 8 & $12 \%$ \\
\hline
\end{tabular}

As a second step, we also wanted to explore the participants' satisfaction with their current employment situation. The outcomes of that question are illustrated in Table 5. A little more than a third of the participants indicated that they were excited about the work that they were doing, while a quarter of them was looking for a different occupation; twenty percent indicated they had good and bad days. Eight participants did not answer this question. Our numbers appear to be similar to a study conducted by the Canadian Centre for Disability Studies (2004), which explored the experiences of 79 students with disabilities transitioning from college and university to employment. That study found that $52 \%$ were employed full time, and $42 \%$ were employed in a field of their choice.

In addition to the overall satisfaction at the workplace, it also mattered to us how satisfied our participants were with the income they received at their workplace. Income levels support or hinder the possibility of living independently, outside of the family home. 22 participants indicated that they were happy with their current income, 22 others wanted to make more money, and one third of the participants did not respond. Given that a significant number of our participants was not employed, we assumed that they did not have an income. It struck us that only a third of the participants were satisfied with their current income. This outcome reflects the literature on the matter, which shows that overall satisfaction with work and income are related to the economic and social context of the employment situation of people with disabilities. Unfortunately, employment is not necessarily meaningful and is often underpaid (Holwerda et al., 2012; Howlin, 2003; Shattuck et al., 2012).

\subsection{Home Life}

This question leads us to a related field, as we were interested in our participants' current living situation. 88\% (n=58) lived with parents and/or family (which corresponds to outcomes of studies in the US; see Novak Amado et al., 2013), and only four were living independently alone or with a roommate. Another four participants were in assisted living group homes.

Table 6. Use of Support Services and Systems

\begin{tabular}{lll}
\hline & $\mathbf{N}$ & $\mathbf{\%}$ \\
\hline Social Services & 11 & $17 \%$ \\
Parents/Family & 10 & $15 \%$ \\
Employment Programs & 9 & $14 \%$ \\
Social Worker & 7 & $11 \%$ \\
None & 7 & $11 \%$ \\
Health Related Services & 4 & $6 \%$ \\
Public Transportation & 4 & $6 \%$ \\
Omitted & 14 & $21 \%$ \\
\hline
\end{tabular}

As a consequence, not surprisingly, ten participants identified their family as a major support service, while social services were mentioned 11 times (Table 6).

The reasons for continuing to live with family were explored more in depth with the participants who participated in the interviews. Most frequently, we heard that participants either did not feel ready to live on their own, or lacked the income necessary to do so. One might add that the lack of creative ways of organizing independent living and lack of knowledge about available resources might also play into both these reasons. The following snippet of an interview contains three statements from our participants, which support these observations. David and his partner had a young daughter and he was working three jobs in order to make a living; however, his income was insufficient to support his young family, so he ended up moving back in with his parents.

I(nvestigator): And so [daughter] lets you sleep in? 
D(avid): She wasn't with me today. I just got, actually, I just got her today, so because I usually get her Thursdays to Sundays, and then I can't have her from Sundays to Thursdays, so...

I: Oh, so you and your partner separated?

D: Yeah.

I: Oh, how long -

D: Well, we're not separated, we're still together, but she lives by herself and I live with my parents for now.

I: Okay.

D: Until I move out again.

I: Oh, because you had already moved out.

D: Yeah, I moved out before, I used to live on Sunshine Street.

I: Why did you end up back home?

D: Uh, just I couldn't afford it by myself.

In contrast, Brian was worried about living by himself, fearing that he would feel too lonely without his family. Studies have shown that loneliness is an issue when it comes to living on one's own (Novak Amado et al., 2013):

Brian: Well like if I live on my own, like, I will have my difficulty time on my own, it's like, it's like being left. Left on the own.

In addition, Brian's mother pointed out that he realized that he would not able to afford an apartment on his own once he considered the income he made at the grocery store.

Lastly, a third participant, Salim, described his family's fears about letting him move out on his own. He indicated that his mother felt he was not ready yet to take this step on his own.

Salim: You know, I'd like to get my own place, but she [mother], uh, she's a little against it, because I don't know why, but... I tell her that eventually I'm going have to do stuff on my own, and she goes, she says uh, eventually but not now.

We cannot make the claim that higher employment numbers and/or higher income levels would bring with it a higher probability for independent living for our surveyed group. The high number of participants still living at home with their parents shows the lack of innovative independent living models across Nova Scotia (and has also been identified as a big social challenge across Canada; see also Burns \& Gordon, 2010). One can also say that this aspect of the ACEE program certainly might need some improvement in terms of the independent living skills that are promoted in workshops, but also that a one-year program is probably not sufficient to support this aspect in a satisfactory way.

\subsection{Transportation}

An aspect closely related to independent living is the mobility of people with disabilities. In a province where public transport has its own struggles because of the culture of driving and low population numbers, we were interested in how our participants were getting around, to either work or to leisure activities. This was especially interesting, as mobility training is an important aspect of the ACEE program, e.g., learning how to read a bus schedule, or how to transfer from one bus to the next.

Table 7. Transportation to work

\begin{tabular}{lll}
\hline & n & \% \\
\hline I take the bus & 40 & $61 \%$ \\
I get dropped off & 16 & $24 \%$ \\
I walk or bike & 3 & $5 \%$ \\
I drive & 1 & $2 \%$ \\
I take the Access-a-bus & 1 & $2 \%$ \\
Omitted & 5 & $8 \%$ \\
\hline
\end{tabular}

Indeed, a majority of the participants were travelling regularly by bus to work (Table 7). Of the entire group, only five participants have a driver's license, and two had a learner's license.

When we asked how they get to places outside of work for leisure activities, such as the swimming pool, gym, and coffee shops, the participants gave almost identical responses. Both outcomes can be considered a positive long term outcome intended by the ACEE program, as learning how to take public transports independently, reading transportation schedules, and being mobile without relying too much on parental support, is strongly encouraged during the year-long 
program, despite the challenges that the local public transport system represents for its users, such as lengthy routes, low frequency, delays, and high rates of transferring.

4.4 Leisure

Another aspect of quality life is to be active outside of work life and to have activities to keep a well-rounded life. Thus, we asked the participants in the survey how often they were involved in those kinds of activities.

Table 8. Leisure Activities

\begin{tabular}{lll}
\hline & $\mathbf{n}$ & $\mathbf{\%}$ \\
\hline A couple of times a month & 23 & $35 \%$ \\
Once a week & 15 & $23 \%$ \\
Several times a week & 12 & $18 \%$ \\
A couple of times a year & 8 & $12 \%$ \\
Hardly ever & 8 & $12 \%$ \\
\hline
\end{tabular}

We observed a high level of engagement, as Table 8 shows. Almost $80 \%$ of the participating alumni are involved into leisure activities at least a few times a month, with $41 \%$ indicating at least once a week.

During the interviews, we examined a little more closely which activities the participants engaged in. There were, of course, home-based activities such as watching television or using the computer. Similar to other youth of this generation, social media activities such as the use of Facebook are very common amongst ACEE alumni and ACEE participants. Many of their networks extend into the virtual world. Novak Amado et al. (2013) indicate that there is currently not enough research to assess properly the impact of social media on the lives of people with disabilities, however, in the case of our study, if definitely supported their connectedness with friends.

The interviews also showed that the ACEE alumni are also active in the community, through volunteering at venues such as a local gallery, which showcases artists with disabilities, or Habitat for Humanity, which builds homes for low-income families. It must be noted that the volunteering activities are not the same as the volunteering in a work place. Here, the goal is recreational, and the participants are giving back to the community.

Finally, there are sports and physical activities, which played a significant role in the lives of the interview participants. Almost all of them were involved into some kind of physical activity, be it swimming, hockey, bowling, or lacrosse, and during discussions about physical activity, the role of the Special Olympics Organization, which is the world's largest sports organization for children and youth with intellectual disabilities crystallized as an important pillar in the lives of many of the participants. This observation might feed into the controversies surrounding the role of the Special Olympics in the literature, as some authors have considered those events to be segregated and outdated (e.g., Storey, 2008; Counsell \& Agran, 2013), whereas others have defended the purpose of the event (MacLean, 2008; Wolfensberger, 1995). For our interview participants, the Special Olympics and their competitions were important events in each of their lives, as they provided a structured environment that included competition, social participation, and events to look forward to during the week. It also provided goals to prepare for. A great deal of pride and joy was evident in their comments:

Barry: [...] I love going outside, I'm trying to lose weight and get in top shape for the Summer Games.

Kate: [...] I'm in bowling, too. And I'm doing really good at bowling. Next time was our last day bowling, then we had a party, I don't know where it is and when and stuff.

As mentioned, the ACEE program is mostly organized and run by Independent Living Nova Scotia (ILNS) staff, and part of the program is to offer its participants social events in which they can partake.

Table 9. Attendance ILNS events

\begin{tabular}{lll}
\hline & $\mathbf{n}$ & $\mathbf{\%}$ \\
\hline I've been to a couple & 32 & $49 \%$ \\
I go every time & 15 & $22 \%$ \\
I never have been but would like to & 8 & $12 \%$ \\
I haven't and I'm not interested & 6 & $9 \%$ \\
Omitted & 5 & $8 \%$ \\
\hline
\end{tabular}

These events are open to all ages, and can comprise things such as picnics, dances, Christmas celebrations, and youth groups. In the survey, we were interested in seeing if the ACEE alumni were still participating in these kinds of events after having graduated from the ACEE program (Table 9). Once more, their responses show a rather good involvement; $22 \%$ said they attend every time, almost half indicated occasional participation, and $12 \%$ indicated they would like to attend. During the interviews, some of the participants declared they would love to attend ILNS events, but were not able to because of their work schedule. Under the lens of social inclusion, those observations are certainly raising the question as to how much inclusiveness those events and organizations are fostering (for an overview of this debate, see 
Novak Amado et al. 2013). However, we cannot discount the enthusiasm that our participants displayed when they talked about attending those events, and the sense of community they experienced as a result. This corresponds to the outcomes of a study by Cummins \& Lau (2003), which addressed the stressfulness of trying to be part of the larger community versus the benefits of spending time within the disability community.

\subsection{Networks}

Lastly, we were not only interested in the alumni's leisure activities, but also in their social networks and friendships. Obviously, both leisure activities and social networks can be very closely connected, and this certainly holds true for our participants. In the survey, we asked how often they were spending time with their friends.

Table 10. Hanging out with friends

\begin{tabular}{lll}
\hline & $\mathbf{n}$ & $\mathbf{\%}$ \\
\hline Several times a week & 34 & $52 \%$ \\
Once a week & 11 & $17 \%$ \\
A couple times a month & 10 & $15 \%$ \\
Hardly ever & 9 & $14 \%$ \\
A couple times a year & 2 & $3 \%$ \\
\hline
\end{tabular}

As one can see from table 10, the ACEE alumni were leading fairly busy social lives, as more than half of them were spending time with their friends several times per week. If one adds those who indicated seeing their friends once a week or a few times per month, their responses painted a picture of more than $80 \%$ of participating ACEE alumni being well connected with friends.

The follow up interviews also showed that many current activities or friendships of the ACEE Alumni originated in the ACEE program. Their colleagues from ACEE constitute a significant part of their social network, and many have forged longstanding friendships. As mentioned before, Facebook, which they are using to stay connected, helps to arrange meetings and get-togethers, such as Anna and Salim described in their interviews:

Anna: Yeah, so like on some weekends, I like hang out with their, like I met some friends from ACEE from this year, so like I invite my friend over for a sleepover, or she invites me over to her house for a sleepover, and then my friend from ACEE from last year, when she was in ACEE with me, sometimes I would go over to her house and sometimes she would come over to my house, and we would like hang out, go for walks, cause there was one time when we went for a walk all the way to the sports stadium, which is like a 20 minute walk from my house.

Salim: Almost everything I do with my friends, except go see hockey games, movies. But go out to eat, go out to the mall sometimes, go to family and friends. Like that kind of stuff.

About half of the interviewees also indicated that they are romantically involved with someone else, currently or in the past. The Special Olympics and the ACEE program were two key meeting points for these relationships. However, some also met at their workplace. The way these relationships manifested varied from person to person. David had a daughter with his partner, Sharon was just getting over a breakup, and Kate talked with her boyfriend over the phone twice a day. Barry had not yet had a girlfriend, but longed to overcome his shyness so he could one day have a relationship with someone (on the topic of overcoming loneliness through having a romantic partner, see also McVilly et al., 2006). Anna had been dating her boyfriend for two months.

I(nvestigator): Where's your boyfriend, you know him from the ACEE program or is that someone from outside?

A(nna): It's someone from outside, because like we're having like new people come in, so he wasn't in the ACEE program, so he actually like asked me out and then I said yes.

I: Oh cool. So how long have you been together?

A: Since March $18^{\text {th }}$.

I: Oh, so your two month anniversary is coming up soon, that's great, that's great. Is he your first boyfriend or did you have boyfriends before?

A: I had lots of boyfriends before, like I had two in the ACEE program, and then some like in high school, because I went to Sackville High, so I had a couple in Sackville High, yeah.

\section{Labor Market Participation versus Social Participation}

The findings of this study give some indicators about the lived reality of young people with disabilities in the province of Nova Scotia. It also offers some insights as to what programs like ACEE or other disability strategies need to focus on in order to improve the lives of people with disabilities. 
Hall $(2009,166)$ found in her meta-analysis of 15 primary research reports that social inclusion emerges in six themes:

1. Being accepted as an individual beyond one's disability,

2. Having relationships, involvement with others that is significant,

3. Involvement in activities,

4. Appropriate living accommodations,

5. Employment,

6. Formal and informal supports

These themes also recur in the present study, and are partly overlapping with the logic model that we followed for the design of this study. Those aspects certainly help us to measure the achievements of the program, but also the elements needing improvement.

The work place experience of the ACEE alumni has been mixed and appears to correspond overall to the Canada-wide labor market participation of people with disabilities, which is not particularly positive and needs strengthening. Thus, on one hand, it was good to see that their employment numbers correspond to the national average, however, one would hope that a program such as ACEE could actually lead to higher employment numbers than average. We observed lower employment numbers starting with the beginning of the years of the world wide economic downturn. Employers appear to have been even more reluctant to employ people with disabilities since that time. The interviews also helped us to see beyond the pure employment numbers of the ACEE alumni, as we heard stories about supervisors who reduced hours (without notice) and against the interest of the employee, and a new supervisor who ultimately let an employee go. It seems that the education of employers and supervising staff needs to be a priority, as access to work and employment is considered a human right for people with disabilities. The work environment is still often only accessible with many supports from job coaches. Once this support (and protection) fades, it appears that the risk of losing the employment becomes much higher. If the parental support is not there (as in the case of Brian and his mother), the risk of the ACEE alumni to be left to his or her own devices increases. As we have pointed out, this is also an issue of social class. The cultural capital of middle class families leads to more beneficial job-searching and job-retention strategies, as the parents are their children's first advocate. Parents are still their children's first support system, but in the interest of equity and increased opportunities for all, not all the responsibility should rest on the shoulder of parents, who are often aging and who might also need a break from the care of their children. There is research to be done related to the fact that people with disabilities are often working in non-unionized environment, which also leaves them more vulnerable to underpayment, inappropriate treatment at the workplace and to losing employment. ${ }^{1}$ It also speaks to the issue that ACEE program has been constructed as a one-year program. Even if continuing support should be part of the support of the alumni, there is not enough staff to make on-the-job issues of former ACEE participants a priority. Furthermore, in the interest of financial independence and choice, there needs to be a reconsideration of wages and work hours, as several participants expressed their willingness to work more hours in order to earn more money. This might not be the case for every participant, where health and other restrictions might interfere with full-time work, but it would be great to see someone like David who supports his little family by working three jobs would actually be able to make ends meet and not obligated to live with his parents again.

On the other hand, we were very positively surprised looking at the social participation of the ACEE alumni, as both the survey and the interviews spoke to very active social lives. If the labor market participation needs to be more supported, the level of involvement of the ACEE alumni in their communities through volunteering, sports, family outings, friendships and intimate relationships is very positive. Most of the ACEE alumni consider themselves as active members of their social groups, and especially through volunteering in different organizations, they are giving back to the community.

Finally, a major issue that needs to be addressed is the low level of independent living amongst the ACEE alumni. As the survey showed, very few of the participants are living on their own, or in alternative housing options. $88 \%$ are living with their families, and to listen to the interviewees, this is not necessarily going to change soon, because of insufficient income, insufficient independence skills, and insufficient housing options for people with disabilities. All three points need to be addressed, as the main weight lies again on the families who continue to support their children, even when this support exceeds their physical and mental forces. Developing flexible housing strategies able to address different levels of independence that are subsidized depending on the income level of each person would make a huge difference

\footnotetext{
${ }^{1}$ To our knowledge, there is no research addressing the issue of unionized workplaces versus non-unionized and their impact on employees with disabilities, however, Jodoin \& Harder (2004) have written about the benefits of developing negotiated contract language in order to reduce the impact of disability in the workplace.
} 
in this field. Obviously, this strategy has to go hand- in- hand with raising the income levels of people with disabilities, so that they are able to sustain themselves as much as possible.

\section{Limitations of This Study}

It appears to us that the data provide some clear ideas about the lived reality of young people with disabilities in Nova Scotia. Nonetheless, this study has some limitations. Firstly, there are limitations in terms of the number of participants. We set out to reach as many alumni of the ACEE program as possible, and ended up connecting with about half of the population that was targeted by the scope of this study. Outdated contact information for many of the alumni was the main reason for not having a bigger sample. Also, while many were willing to participate in the survey part of the study, the numbers considerably diminished when it came to participating in the interviews,, as only $1 / 6$ of our participants agreed to follow up with us.

Secondly, our methodology, despite having a mixed methods approach, could not cover for everything. We tried to keep the survey simple, short and accessible for a population considered to have a (learning) disability. Participants filled out the survey with the help of assistants who were trained to not influence the responses, but there is a risk that responses were influenced by the mere presence of the research assistants.

Lastly, this study did not focus in particular on a certain type of impairment, but chose as the only criterion to be an alumnus of the ACEE program. We also chose to not collect data on the types of impairment, and leave it up to the participants if they wished to identify their areas of strengths and challenges. Nonetheless, we can make the assumption that all participants are having access to literacy and numeracy skills, as the nature of the ACEE program requires a certain skill level from its participants. Thus, the findings are speaking for this particular group and cannot be simply adapted to any group of persons with disabilities.

\section{Conclusion}

In conclusion, researching this group of young people on their way to adulthood drew an amazing picture of a cohort of people in their twenties who are mostly positive, engaged young people, who are trying very hard to construct their lives and their future during times of adverse conditions. It was remarkable to hear their optimism and their resilience through their words in the interviews and in conversations surrounding the surveys. One can certainly hope that the promotion and refinement of programs such as ACEE will help those young people to reach their goals and they become more and more able to lead satisfying and independent lives within the community. The findings have also revealed that work needs to be done by the community and workplaces to create more welcoming and accessible spaces for people with disabilities. This might be another important aspect to emphasize even more in programs such as ACEE: the education of employers and community members about diversity and the changes to be made to achieve more inclusion, accessibility and participation.

The methodology of this project proved yet once more to be empowering as these young people were able to express themselves in very articulate ways (see also Barnes 2003), and gave us a strong impression about their identities, their needs and their future aspirations. Another follow up should be done in order to see what will happen for this group when they are entering their 30 s.

\section{References}

Atkinson, D. (2004). Research and empowerment: involving people with learning disabilities in oral and life history research, Disability \& Society, 19, 691-702. http://dx.doi.org/10.1080/0968759042000284187

Barnes, C. (2003). What a difference a decade makes: Reflections on doing 'emancipatory' disability research. Disability \& Society, 18(1), 3-17. http://dx.doi.org/10.1080/713662197

Blanck, P. D. (2004). Disability, civil rights law, and policy. St. Paul, MN: Thomson/West.

Breslin, M. L., \& Yee, S. (2002). Disability Rights Education and Defense Fund. Disability rights law and policy: International and national perspectives. Ardsley, NY: Transnational Publishers.

Burns, K. K., \& Gordon, G. L. (2010). Analyzing the Impact of Disability Legislation in Canada and the United States. Journal of Disability Policy Studies, 20, 205. http://dx.doi.org/10.1177/1044207309344562

Campbell, J., \& Oliver, M. (1996). Disability politics: understanding our past, changing our future. London: Routledge.

Canadian Centre for Disability Studies (2004). Students with Disabilities: Transitions from Post- Secondary Education to Work: Phase II Report. Winnipeg, Manitoba.

Cavet, J., \& Sloper, P. (2004). Participation of disabled children in individual decisions about their lives and in public decisions about service development. Children \& Society, 18(4), 278-290. http://dx.doi.org/10.1002/chi.803

Chambers, D., Rabren, K., \& Dunn, C. (2009). A comparison of transition from high school to adult life of students with 
and without disabilities. Career Development for Exceptional Individuals, 32, 42-52. http://dx.doi.org/10.1177/0885728808323944

Charlton, J. (1998). Nothing about us without us: Disability oppression and empowerment. Berkeley: University of California Press. http://dx.doi.org/10.1525/california/9780520207950.001.0001

Counsell, S., \& Agran, M. (2013). Understanding the Special Olympics debate from life-world and system perspectives: Moving beyond the liberal egalitarian view toward empowered recreational living. Journal of Disability Policy Studies, 23(4), 245-256. http://dx.doi.org/10.1177/1044207312450751

Cummins, R. A., \& Lau, A. L. D. (2003). Community integration or community exposure? A review and discussion in relation to people with an intellectual disability. Journal of Applied Research in Intellectual Disabilities, 16(2), 145-157. http://dx.doi.org/10.1046/j.1468-3148.2003.00157.x

Davis, J. M., Watson, N., \& Cunningham-Burley, S. (2000). Learning the lives of disabled children. Developing a reflexive approach. In P. Christensen, \& A. James (Eds.), Research with children, Perspectives and practices (pp. 201-224) Routledge Falmer.

Hall, S. A. (2009). The social inclusion of people with disabilities: A qualitative meta-analysis. Journal of Ethnographic \& Qualitative Research, 3(3), 162-173. Retrieved from

http://ezproxy.msvu.ca/login?url=http://search.ebscohost.com/login.aspx?direct=true\&db=aph\&AN=39755817\&si te $=$ ehost-live\&scope $=$ site

Holwerda, A., van der Klink, J. J. L., Groothoff, J. W., \& Brouwer, S. (2012). Predictors for work participation with an autism spectrum disorders: A systematic review. Journal of Occupational Rehabilitation 22, 333-352. http://dx.doi.org/10.1007/s10926-011-9347-8

Howlin, P. (2003). Longer-term educational and employment outcomes. In M. Prior (Ed.), Learning and behavior problems in Asperger syndrome (pp. 269-293). New York, NY: Guilford Press

Human Resources and Skills Development Canada (2006). Disability in Canada: A 2006 Profile. Retrieved at http://www.esdc.gc.ca/eng/disability/arc/disability_2006.shtml, accessed on January $2^{\text {nd }} 2015$

Jodoin, S., \& Harder, H. (2004). Strategies to enhance labour-management cooperation in the development of disability management programs. International Journal of Disability, Community and Rehabilitiation, 3(4). Retrieved from http://www.ijdcr.ca/VOL03_04_CAN/articles/jodoin.shtml

MacLean, W. E. Jr. (2008). Special Olympics: The rest of the storey. Research \& Practice for Persons with Severe Disabilities, 33(3), 146-149. http://dx.doi.org/10.2511/rpsd.33.3.146

McDonnell, J., \& Hardman, M. L. (2010). Successful transition programs: Pathways for students with intellectual and developmental disabilities $\left(2^{\text {nd }}\right.$ ed.). Thousand Oaks, CA: Sage.

McVilly, K. R., Stancliffe, R. J., Parmenter, T. R., \& Burton-Smith, R. (2006). 'I get by with a little help from my friends': Adults with intellectual disability discuss loneliness. Journal of Applied Research in Intellectual Disabilities, 19(2), 191-203. http://dx.doi.org/10.1111/j.1468-3148.2005.00261.x

Newman, L., Wagner, M., Knokey, A. M., Marder, C., Nagle, K., Shaver, D., ... Schwarting, M. (2011). The Post-High School Outcomes of Young Adults With Disabilities up to 8 Years After High School. A Report from the National Longitudinal Transition Study-2 (NLTS2) (NCSER 2011-3005). Menlo Park, CA: SRI International, retrieved at http://nlts2.org/reports/2011_09_02/nlts2_report_2011_09_02_execsum.pdf

Novak, A. A., Stancliffe, R. J., McCarron, M., \& McCallion, P. (2013). Social inclusion and community participation of individuals with Intellectual/Developmental disabilities. Intellectual \& Developmental Disabilities, 51(5), 360-375. http://dx.doi.org/10.1352/1934-9556-51.5.360

Schneider, C. (2010). 'Ready for work': feeling rules, emotion work and emotional labour for people with disabilities, Interactions, vol. 4; retrieved at

http://dc.msvu.ca:8080/xmlui/bitstream/handle/10587/1601/schneider_en.pdf?sequence=1\&isAllowed=y

Shattuck, P. T., Narendorf, S. C., Cooper, B., Sterzing, P. R., Wagner, M., \& Taylor, J. L. (2012). Postsecondary and employment among youth with an autism spectrum disorder. Pediatrics. Pediatrics, 129(6), 1042-1049. http://dx.doi.org/10.1542/peds.2011-2864

Storey, K. (2008). The more things change, the more they are the same: Continuing concerns with the Special Olympics. Research \& Practice for Persons with Severe Disabilities, 33(3), 134-142. http://dx.doi.org/10.2511/rpsd.33.3.134

Trainor, A. A. (2008). Using social and cultural capital to improve postsecondary outcomes and expand transition 
models for youth with disabilities. Journal of Special Education, 42, 148-162. http://dx.doi.org/10.1177/0022466907313346

Trainor, A. A. (2010). Re-examining the promise of parent participation in special education: An analysis of cultural and social capital. Anthropology and Education Quarterly, 41, 245-263. http://dx.doi.org/10.1111/j.1548-1492.2010.01086.x

United Nations (2003). Standard rules on the equalization of opportunities of persons with disabilities. New York: United Nations.

Wagner, M., Cadwallader, T., \& Marder, C. (2003). Life outside the classroom for youth with disabilities. Menlo Park, CA: SRI International.

Wagner, M., Newman, L., Cameto, R., Levine, P., \& Marder, C. (2003). Going to school: Instructional contexts, programs, and participation of secondary school students with disabilities. Menlo Park, CA: SRI International.

Wehman, P. (2006). Individualized transition planning: Putting self-determination into action. In P. Wehman (Ed.), Life beyond the classroom: Transition strategies for young people with disabilities (pp. 71-96). Baltimore, MD: Brookes.

Wehmeyer, M. L., \& Palmer, S. B. (2003). Adult outcomes for students with cognitive disabilities three-years after high school: The impact of self-determination. Education and Training in Developmental Disabilities, 38, $131-144$.

Wolfensberger, W. (1995). Of "normalization," lifestyles, the Special Olympics, deinstitutionalization, mainstreaming, integration, and cabbages and kings. Mental Retardation, 33(2), 128-131. Retrieved from http://ezproxy.msvu.ca/login?url=http://search.ebscohost.com.ezproxy.msvu.ca/login.aspx?direct=true\&db=eft\&A $\mathrm{N}=508552919$ \&site $=$ ehost-live\&scope $=$ site

\section{$(\mathrm{cc}) \mathrm{EY}$}

This work is licensed under a Creative Commons Attribution 3.0 License. 